Journal of Research in
Nanoscience and Nanotechnology
Journal homepage:
Akwdemia Baru
ISSN: 2773-6180

\title{
Synthesis and Characterization of Sn/Ag Nanoparticle Composite as Electro-Catalyst for Fuel Cell
}

\author{
Tan Wei Kang ${ }^{1}$, Siti Husnaa Mohd Taib ${ }^{1}$, Pooria Moozarm Nia ${ }^{2}$, Mikio Miyake \\ ${ }^{3}$ and Kamyar Shameli ${ }^{1, *}$
}

Malaysia-Japan International Institute of Technology, Universiti Teknologi Malaysia, Jalan Sultan Yahya Petra, 54100 Kuala Lumpur, Malaysia ${ }^{1}$

Centre of Hydrogen Energy (CHE), Institute of Future Energy, Universiti Teknologi Malaysia, Jalan Sultan Yahya Petra, 54100 Kuala Lumpur, Malaysia ${ }^{2}$

Japan Advanced Institute of Science and Technology (JAIST), Asahidai, Nomi, Ishikawa

923-1292, Japan ${ }^{3}$

* Correspondence: kamyarshameli@gmail.com; Tel.: +6017 3443492

https://doi.org/10.37934/jrnn.1.1.1221

\section{ABSTRACT}

In this research, $\mathrm{Sn} / \mathrm{Ag}$ nanoparticle composite was produced by using chemical reduction method with the aids of sodium borohydride as reducing agent and sodium succinate as protective agent. The XRD, EDX, and TEM analyses showed that the Sn/Ag nanoparticle composite was formed with an average particle size of $4.37+0.44 \mathrm{~nm}$. For the application, LSV analysis was done on Sn nanoparticle and Sn/Ag nanoparticle composite samples, and the analysis showed current produced from $\mathrm{Sn} / \mathrm{Ag}$ nanoparticle composite $(4.10 \times$ $10-6 \mathrm{~A})$ is higher than $\mathrm{Sn}$ nanoparticle $(3.47 \times 10-6 \mathrm{~A})$ at the potential of $-0.83 \mathrm{~V}$.

Keywords:

$\mathrm{Sn} / \mathrm{Ag}$ nanoparticles, electro-catalyst, polymer electrolyte membrane fuel cell, linear sweep voltammetry.

Received: 12 December $2020 \quad$ Revised: 27 December $2020 \quad$ Accepted: 29 January $2021 \quad$ Published: 28 February 2021

\section{Introduction}

The nanoparticle (NPs) could be defined as an object which is less than $100 \mathrm{~nm}$ in all the three Cartesian dimensions [1]. Nowadays, metal NPs composite poses a high interest in various scientific fields [2-4]. Many researchers are involving themselves in this metal NPs composite research. This is because by producing NPs composite, it can create unique properties such as work function and surface energy [5,6]. Therefore, NPs composite owns a huge potential in many areas such as catalytic, magnetic, plasmonic, electronic and so on [7].

Fuel cell is a device which generates energy by converting chemical energy from the continuously supplied fuel into electrical energy with negligible environmental effect [8]. Among all fuel cells 
available, Polymer Electrolyte Membrane fuel cell (PEMFC) gains the highest attention because of its simple structure, quick start-up, low operating condition, high energy density and insignificant environmental effects [8]. PEMFC uses hydrogen and oxygen from air as fuel to produce water and electricity as by-product [9]. The reactions involved in the fuel cell are hydrogen oxidation reaction (HOR) and oxygen reduction reaction (ORR). In the anode, HOR is occurred to give away electrons and protons which are transferred to the cathode. The half-reaction at the anode is $\mathrm{H}_{2} \rightarrow 2 \mathrm{H}^{+}+2 \mathrm{e}^{-}$. Meanwhile, in the cathode, ORR is happened to produce water by receiving electrons and protons from anode. The half-equation at the cathode is $1 / 2 \mathrm{O}_{2}+2 \mathrm{H}^{+}+2 \mathrm{e}^{-} \rightarrow \mathrm{H}_{2} \mathrm{O}$ [5].

For ORR, it is found that the most appropriate with highest efficiency catalyst for this half-reaction is Pt-based catalyst [8]. However, the scarce and high market price of Pt metal had led to difficulty in the commercialization of PEM fuel cell. This syndrome had caused the researchers would like to reduce the usage of $\mathrm{Pt}$ and even use other abundant and cheap metal to replace $\mathrm{Pt}$ completely [10]. The latter option is more preferred as compared to former option. In order to replace Pt completely, Palladium (Pd) also is one of the alternative metals which could be used to replace Pt since $\mathrm{Pd}$ is located at the same group as Pt and show a good performance toward catalysis of ORR [11]. However, performance of Pd-based NPs catalyst toward ORR is around 5 times lower than Pt-based NPs catalyst and the market price of Pd is still comparatively higher than most of the metals [11]. Some oxides of metals such as transition metal, carbon group (group 14) metal, nitrogen group (group 15) metal are used to produce catalyst for ORR. Although these metals are found to be able to increase the rate of ORR and cheaper than $\mathrm{Pt}$, their activities and performances are significantly lower than Pt-based catalyst [10].

Metal NPs composite also owns a huge potential to be a catalyst with high efficiency and low cost and even replace conventional catalysts such as Platinum $(\mathrm{Pt})$ in various areas such as fuel cells. Nonetheless, to invent a new metal NPs composite catalyst, the characteristics and properties of respective metal components and the cost of manufacturing that catalyst should be taken into consideration. Recently, there are a lot of research done on synthesis of various metal NPs to investigate their electro-catalytic performance in fuel cell [12-14]. In this research paper, Sn and Ag are selected to be synthesized to be bimetallic NPs composite which works as fuel cell catalyst. The reasons for selecting $\mathrm{Sn}$ are that $\mathrm{Sn}$ resource is abundant, and its market price is much lower than conventional metals for ORR catalyst such as Pt and Pd [10], although limited research was done on synthesis of Sn NPs composite as electro-catalyst for fuel cell [15]. Meanwhile, the reasons for choosing Ag as this fuel cell catalyst NPs composite is that Ag has a high ORR activity, high stability in alkaline media, and relatively low cost [16]. In addition, Ag is significantly stable in alkaline medium thermodynamically and electrochemically [17]. Ag had proven by several researchers that it is suitable to be one of the candidates for NPs composite for ORR catalyst [18-27]. Some research was done on synthesizing Sn/Ag NPs composite for the application of lead-free soldering [28, 29]. However, none of the research is done to synthesize Sn/Ag NPs composite and investigate its possibility as electro-catalyst for fuel cell.

The goal of this research is to determine the potential of Sn/Ag NPs composite to be the electrocatalyst for fuel cell. In order to achieve that objective, Sn NPs and Sn/Ag NPs composite are synthesized by using chemical reduction method. Sodium succinate is used as the protective agent during synthesis of NPs sample [7]. The Sn/Ag NPs sample was synthesized in Sn:Ag ratio of 4:1. Then, Sn NPs and Sn/Ag NPs composite prepared are used to conduct electrochemical analysis for fuel cell. Next, their electro-catalytic efficiencies in fuel cell are analysed and compared. 


\section{Materials and Methods}

\subsection{Chemicals}

Sn NPs sample was prepared from tin (II) chloride $\left(\mathrm{SnCl}_{2}\right)$, sodium borohydride $\left(\mathrm{NaBH}_{4}\right)$ and sodium succinate $\left(\mathrm{C}_{6} \mathrm{H}_{4} \mathrm{Na}_{2} \mathrm{O}_{4} \cdot 6 \mathrm{H}_{2} \mathrm{O}\right)$ meanwhile $\mathrm{Sn} / \mathrm{Ag}$ NPs composite sample was synthesized by using tin (II) chloride $\left(\mathrm{SnCl}_{2}\right)$, silver nitrate $\left(\mathrm{AgNO}_{3}\right)$ sodium borohydride $\left(\mathrm{NaBH}_{4}\right)$ and sodium succinate $\left(\mathrm{C}_{6} \mathrm{H}_{4} \mathrm{Na}_{2} \mathrm{O}_{4} \cdot 6 \mathrm{H}_{2} \mathrm{O}\right)$. In electrochemical analysis, $5 \mathrm{wt}$. \% of nafion solution was prepared from the Aldrich stock solution. All the chemicals above were purchased from Sigma Aldrich. And also, all the chemicals were analytical grade classes in powder form and were used without further process or alteration. Deionised (DI) water was used throughout the experiment.

\subsection{Synthesis of $S n N P S$}

Synthesis of Sn NPs was done by reduction of $\mathrm{Sn}^{2+}$ ion from tin (II) chloride by using sodium borohydride (reducing agent) in the presence of sodium succinate (protective agent). For the preparation of $60 \mathrm{~mL}$ of $0.02 \mathrm{M}$ tin (II) chloride solutions, it was done by dissolving $0.2275 \mathrm{~g}$ tin (II) chloride powder in $60 \mathrm{~mL}$ DI water. For $60 \mathrm{~mL}$ of $0.2 \mathrm{M}$ sodium succinate, it was done by dissolving $3.2417 \mathrm{~g}$ of sodium succinate powder in $60 \mathrm{~mL}$ DI water. Meanwhile, for the preparation of $10 \mathrm{~mL}$ of $0.6 \mathrm{M}$ sodium borohydride solution, it was done by dissolving $0.2270 \mathrm{~g}$ of sodium borohydride powder in $10 \mathrm{~mL}$ DI water. Next, tin (II) chloride solution was added into sodium succinate solution. After that, the sodium borohydride solution was added slowly drop by drop by using dropper into the prepared tin (II) chloride solution while it was stirred vigorously at speed of $600 \mathrm{rpm}$. The process of stirring will be continued for 12 hours at $25{ }^{\circ} \mathrm{C}$. The synthesized Sn NPs that were in suspension form was poured in centrifugal tubes. The samples were then centrifuged at $4000 \mathrm{rpm}$ by using Kubota Model 2800 centrifugal for 10 minutes and then rinsed with DI water. The steps of centrifuging and rinsing were repeated for 3 times. After being centrifuged, the sample was dried in the oven at $35^{\circ} \mathrm{C}$ until it is dried completely.

\subsection{Synthesis of Sn/Ag NPs composite}

Synthesis of Sn/Ag NPs composite was done by reduction of $\mathrm{Sn}^{2+}$ ions from tin (II) chloride and then followed by reduction of $\mathrm{Ag}^{+}$ions from silver nitrate by using sodium borohydride in the presence of sodium succinate. In detailed, $60 \mathrm{~mL}$ of $0.02 \mathrm{M}$ tin (II) chloride solution was prepared by dissolving $0.2275 \mathrm{~g}$ of tin (II) chloride powder in $60 \mathrm{~mL}$ DI water. $60 \mathrm{~mL}$ of $0.2 \mathrm{M}$ sodium succinate solution was prepared by dissolving $3.2417 \mathrm{~g}$ of sodium succinate powder in $60 \mathrm{~mL}$ DI water. $10 \mathrm{~mL}$ of $0.6 \mathrm{M}$ and $5 \mathrm{~mL}$ of $0.3 \mathrm{M}$ sodium borohydride solution were prepared by dissolving $0.2270 \mathrm{~g}$ and $0.0567 \mathrm{~g}$ of sodium borohydride powder in a $10 \mathrm{~mL}$ and $5 \mathrm{~mL}$ of DI water, respectively. Meanwhile, $15 \mathrm{ml}$ of $0.02 \mathrm{M}$ silver nitrate solution was prepared by dissolving $0.0510 \mathrm{~g}$ of silver nitrate powder in $15 \mathrm{~mL}$ DI water. Then, tin (II) chloride solution was added into the sodium succinate solution. $10 \mathrm{~mL}$ of sodium borohydride solution was added drop by drop by using dropper into the mixture solution just now while it was stirred vigorously at speed of $600 \mathrm{rpm}$. The stirring process was continued for 12 hours at $25^{\circ} \mathrm{C}$.

\subsection{Characterization of prepared sample}

X-Ray Diffraction (XRD) analysis was conducted by using PANalytical X-ray diffractometers with $\mathrm{Cu} \mathrm{K} \alpha$ radiation $(\lambda=1.54060 \AA$ ) operating at $40 \mathrm{~mA}$ and $45 \mathrm{kV}$. The XRD patterns obtained with a step 
size in the $2 \theta$ scan of $0.026^{\circ}$ over the range of $10-90^{\circ}$. The surface topography of the NPs samples prepared was investigated in field emission scanning electron microscopy (FE-SEM) analysis with aid of JSM-7800F Field Emission Scanning Electron Microscope equipped with an energy dispersive spectrometer (EDS). Fourier Transform Infrared (FT-IR) spectra of sample and KBr powder mixture pressed pellets were recorded using a Spotlight 200i FT-IR Microscope. The size and lattice distance of nanoparticles in Sn NPs and Sn/Ag NPs composite sample were determined in transmission electron microscopy (TEM) analysis by using JEM-2100F Field Emission Electron Microscope.

\subsection{Electrochemical analysis on prepared sample}

Electrochemical analysis was conducted in order to investigate the catalytic performance of Sn NPs and Sn/Ag NPs composite samples prepared. The method used to analyse the performance of samples is linear sweep voltammetry (LSV). $3.6 \mu \mathrm{L}$ of sample suspension was dropped on the GC electrode surface and let to dry. Then, $1.6 \mu \mathrm{L}$ of $5 \%$ nafion was dropped on the GC electrode surface and let to dry. The measurement was carried out in saturated gas conditions, which were oxygen $\left(\mathrm{O}_{2}\right)$ and nitrogen $\left(\mathrm{N}_{2}\right)$. The analysis was conducted by using VersaSTAT3 Potentiostat Galvanostat at voltage range from $0.0 \mathrm{~V}$ to $-1.5 \mathrm{~V}$ with step size of $0.00244 \mathrm{~V}$.

\section{Results and Discussion}

\subsection{Characterization study on samples}

For XRD analysis, the data was analysed by using X'Pert HighScore Plus software. Based on the Figure 1(a), the observable peaks at [200], [101], [220], [211], [301], [112], [400], [321], [420], [411], [312], and [431] correspond to tetragonal-phase Sn (JCPDS file no. 01-089-4898) were found from the sample's spectrum. Hence, it could be deduced that the Sn was present in the sample synthesized. However, there were still some observable peaks at [110], [101], [200], [111], [211], [220] and [310] which originated tetragonal phase of tin (II) oxide (SnO) (JCPDS file no. 00-007-0159). This showed that some Sn from surface of the sample was oxidized as no chemical was used to prevent $\mathrm{Sn}$ from being further oxidized. For Figure 1(b), the observable peaks at [200], [101], [220], [211], [301], [112], [420], [411], [312], and [431] correspond to tetragonal-phase Sn (JCPDS file no. 01-089-4898) and also peaks at [111], [200], [220], [311] and [222] which corresponding to face-centered cubic structure of Ag (JCPDS file no. 01-089-3722) were found in the XRD spectrum for Sn/Ag sample prepared. However, there were still some peaks at [110], [101], [111], [211] and [220] which come from SnO. This shows that some $\mathrm{Sn}$ from surface of the sample was oxidized. 


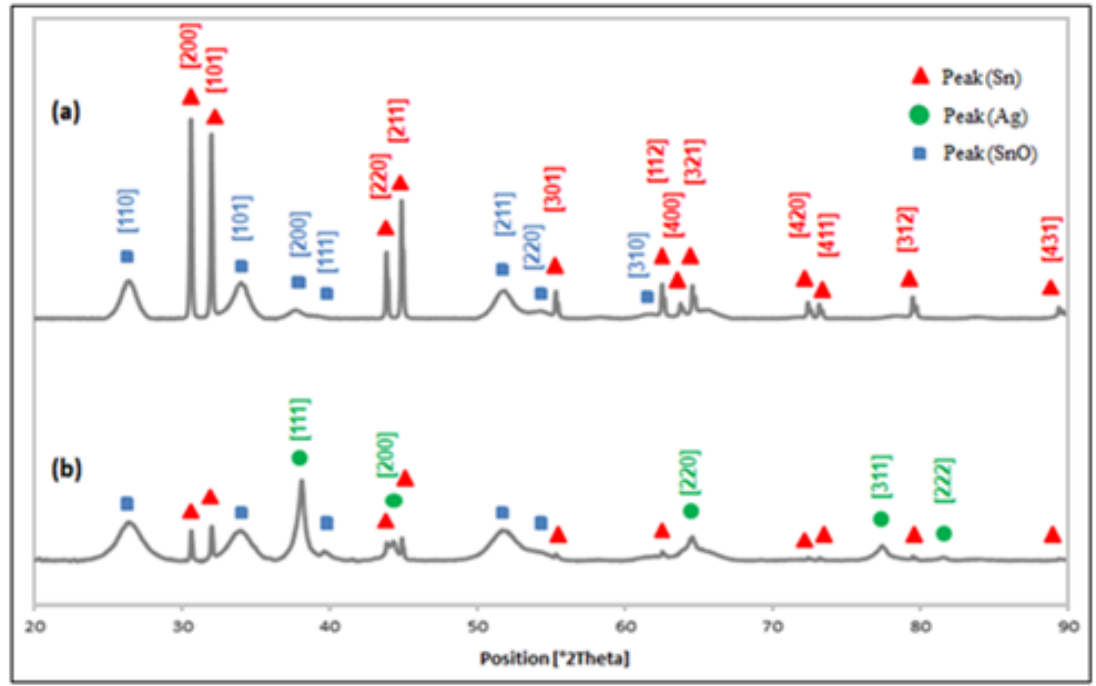

Figure 1. XRD pattern of (a) Sn NPs sample and (b) Sn/Ag NPs composite sample.

Figure 2(a) and (c) show the FESEM images of Sn NPs and Sn/Ag NPs composite. In Figure 2, the Sn NPs and Sn/Ag NPs had undergone agglomeration. This shows that the role of sodium succinate as protective agent was not effective during synthesis of Sn and Sn/Ag NPs composite samples. The Energy-Dispersive X-ray (EDX) spectroscopy analysis was carried out at the same instrument as FESEM analysis and the result spectra are shown in Figure 2(b) and (d). In Figure 2(b), Sn NPs sample consisted of three elements which are tin $(\mathrm{Sn})$, oxygen $(\mathrm{O})$ and carbon $(\mathrm{C})$. Oxygen peak in the analysis result might be originated from $\mathrm{SnO}$ or succinate molecules on the NPs sample prepared meanwhile Carbon peak might come from succinate or carbon coating. Based on the atomic percentage of $\mathrm{Sn}$ $(45.96 \%)$ to O $(25.66 \%)$ in the analysis, we could prove that the Sn NPs sample had high content of pure Sn NPs in the sample. In Figure 2(d), Sn/Ag NPs sample consisted of three elements which are tin (Sn), silver (Ag) and oxygen (O). The atomic percentage of $\mathrm{Sn}(51.64 \%)$ was about four times higher than $\mathrm{Ag}(14.82 \%)$ as the amount of $\mathrm{Sn}$ source used was four times higher than the amount of $\mathrm{Ag}$ source used during synthesis process.

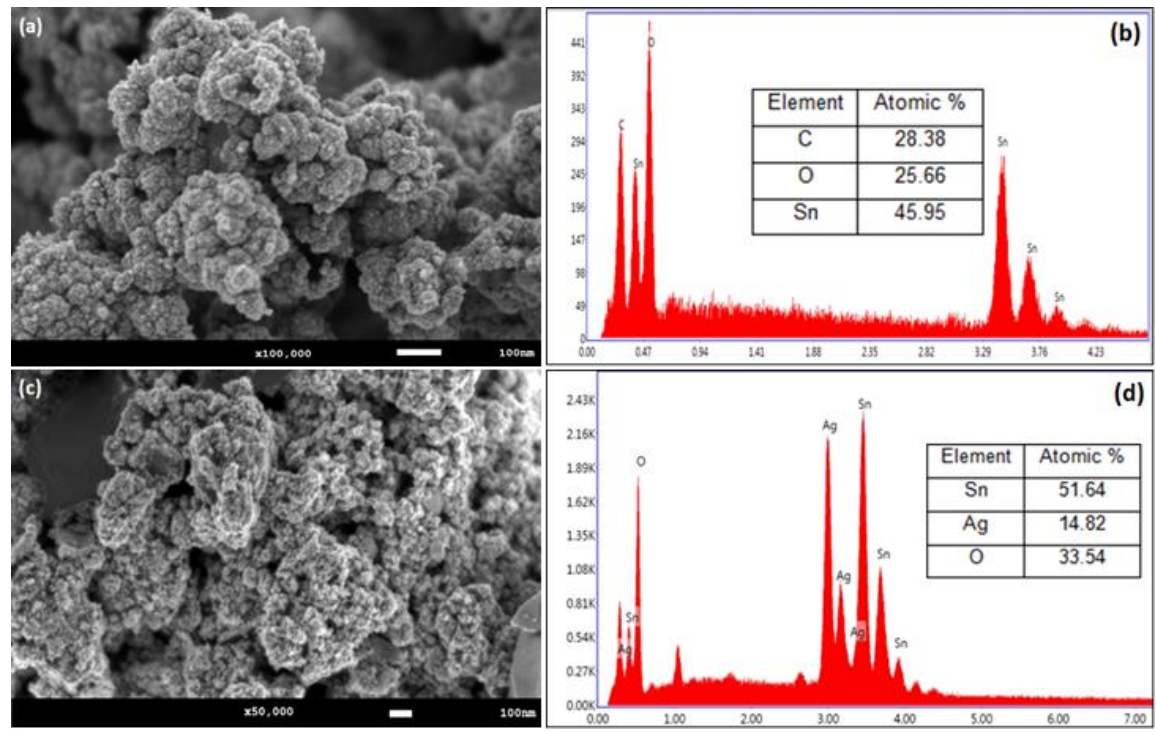

Figure 2. FESEM images of (a, c) Sn NPs sample and Sn/Ag NPs composite sample and EDX spectra of (b, d) Sn NPs sample and Sn/Ag NPs composite sample. 
FTIR analysis was done for determining the presence of succinate as protective agent in both samples synthesized. The FTIR spectra for Sn NPs and Sn/Ag NPs composite samples are illustrated in Figure 3(a) and (b). Peaks for O-H stretch were present at $3401 \mathrm{~cm}^{-1}$ for Sn NPs while $3439 \mathrm{~cm}^{-1}$ for $\mathrm{Sn} / \mathrm{Ag}$ NPs composite. C-H stretching peak only visible in Sn/Ag NPs composite sample at $2921 \mathrm{~cm}^{-1}$ but not in Sn NPs sample. The $\mathrm{C}=\mathrm{O}$ stretching peaks were identified at $1631 \mathrm{~cm}^{-1}$ for Sn NPs and 1558 $\mathrm{cm}^{-1}$ for Sn/Ag NPs composite. All the organic bonds identified above are corresponding to succinate molecules. However, the adsorption bands at $624 \mathrm{~cm}^{-1}$ and $634 \mathrm{~cm}^{-1}$ for Sn NPs and Sn/Ag NPs composite respectively were represented $\mathrm{Sn}-\mathrm{O}$ bond which come from $\mathrm{SnO}$ in both samples [29].

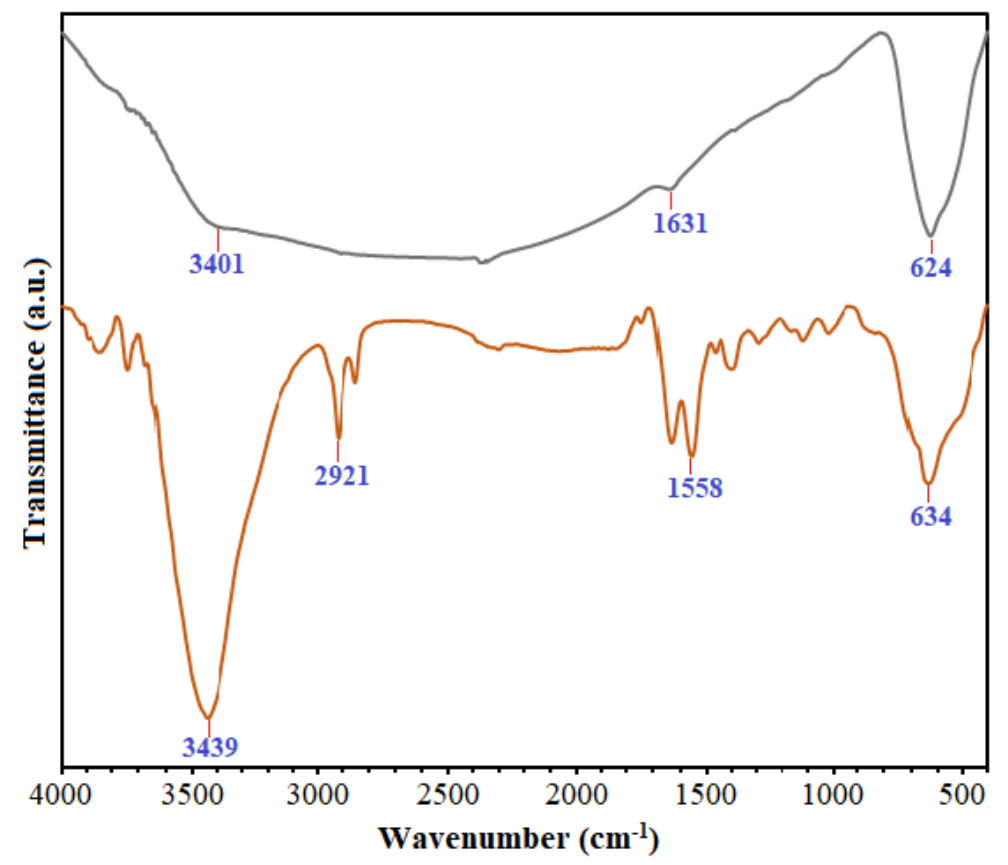

Figure 3. FTIR spectra for (a) Sn NPs and (b) Sn/Ag NPs composite sample.

In TEM analysis, particle size and lattice distance of the NPs were determined. For measuring particle size, 123 nanoparticles were randomly picked and measured, and the average particle size was calculated based on sizes of 123 nanoparticles. In Figure 4(b), the average size of nanoparticles in Sn NPs was estimated to be $5.45 \pm 0.68 \mathrm{~nm}$. Meanwhile in Figure 4(d), the average size of nanoparticles in Sn/Ag NPs composite is $4.37 \pm 0.44 \mathrm{~nm}$. In Figure 5(a), there were 2 different lattice distances identified, which were around $0.319 \mathrm{~nm}$ which corresponding to Sn [30] and $0.379 \mathrm{~nm}$ which corresponding to $\mathrm{SnO}$ [31]. In Figure 5(b), the 2 lattice distances detected were $0.318 \mathrm{~nm}$ and 0.408 $\mathrm{nm}$, which were coincided with lattice constants for Sn [28] and Ag [32]. 

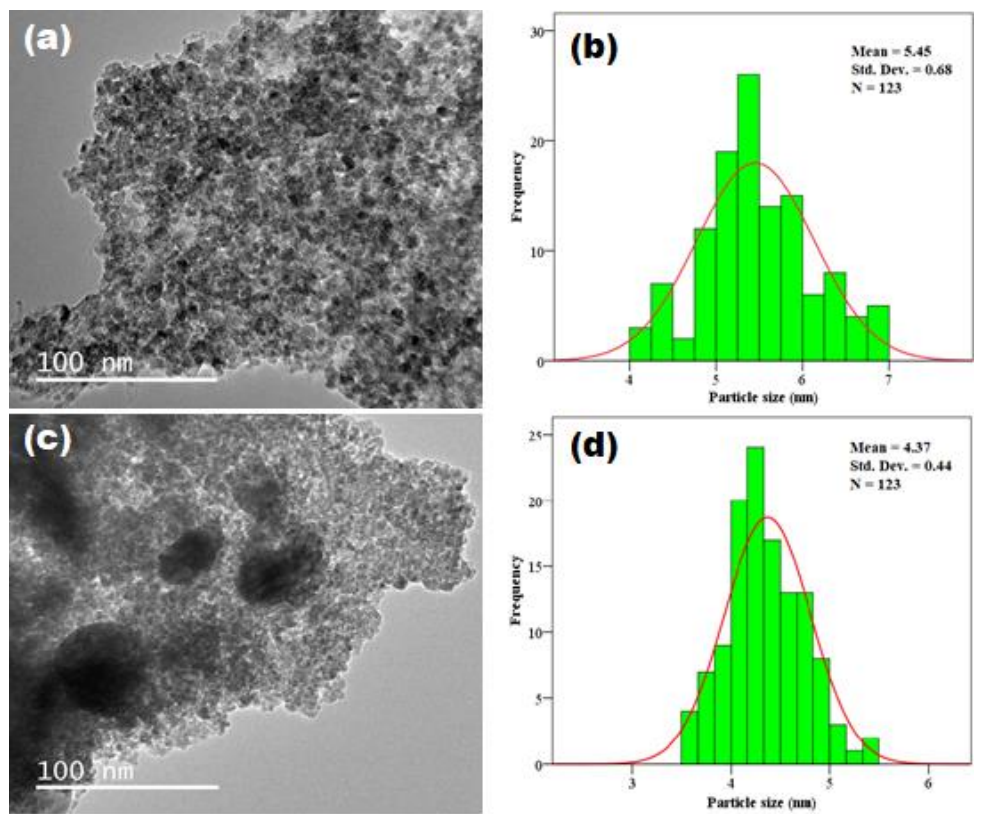

Figure 4. TEM images of (a) Sn NPs and (c) Sn/Ag NPs composite; histogram of particle size distribution of (b) Sn NPs and (d) Sn/Ag NPs composite.
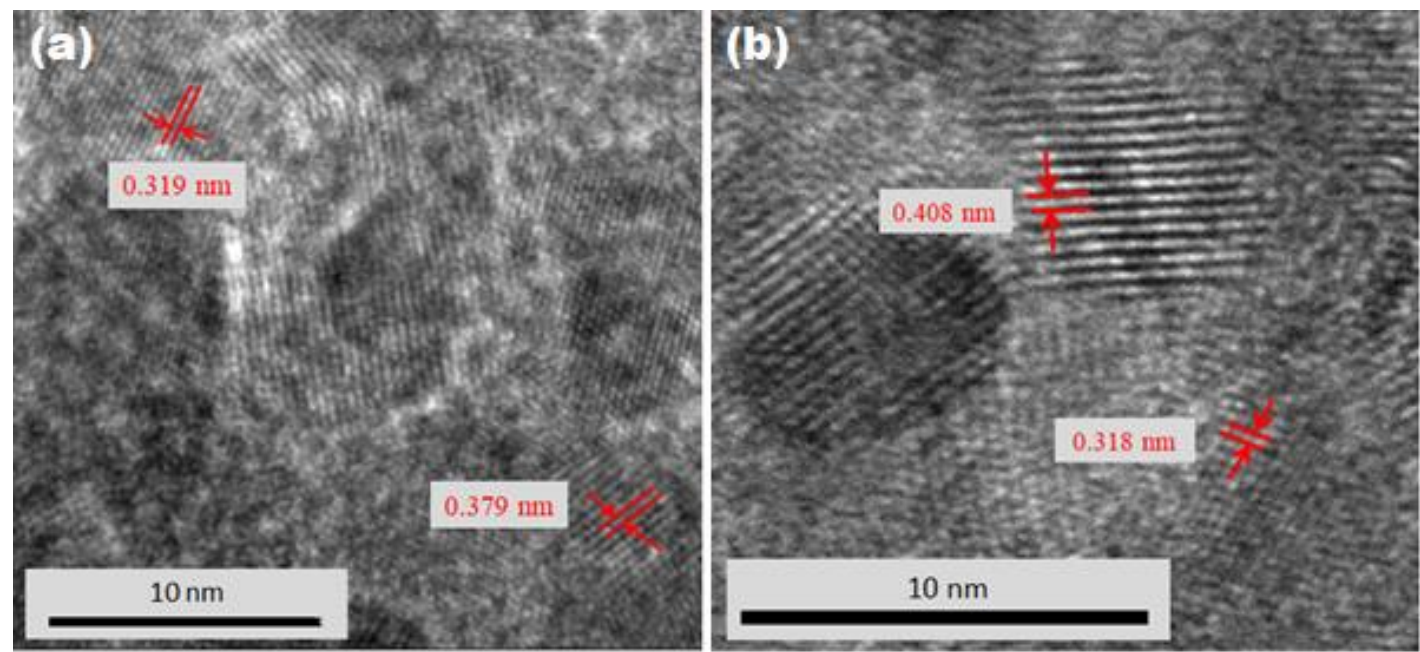

Figure 5. TEM images of (a) Sn NPs and (b) Sn/Ag NPs composite.

\subsection{Electrochemical characterization on samples}

As shown in Figure 6, the electro-catalytic efficiencies for both Sn NPs and Sn/Ag Nps composite samples determined in LSV analysis were plotted. In Figure 6, at potential of $-0.83 \mathrm{~V}$ where the reaction was occurred, for $\mathrm{Sn} / \mathrm{Ag}$ NPs composite sample, the current produced was $4.10 \times 10^{-6} \mathrm{~A}$ and it was greater than current produced from using Sn NPs sample which was $3.47 \times 10^{-6} \mathrm{~A}$. 


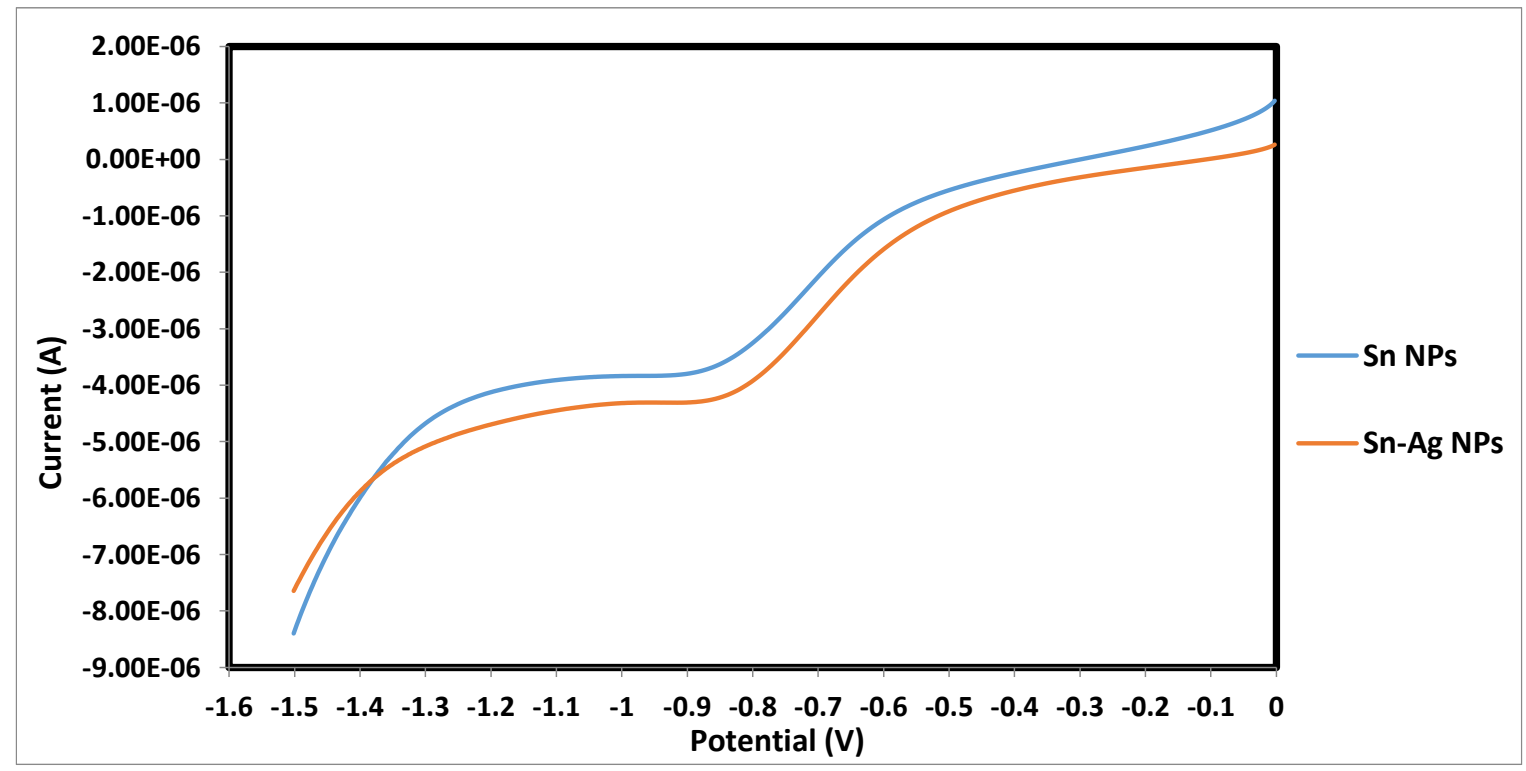

Figure 6. Comparison on LSV analysis results for Sn NPs and Sn/Ag NPs composite samples.

\section{Conclusions}

Based on the results of XRD, EDX, FTIR and TEM analyses, it could be concluded that Sn/Ag NPs composite was successfully synthesized by using the chemical reduction method. The XRD results indicate that Sn/Ag NPs composite sample contained metallic Sn and Ag with SnO. Meanwhile EDX results showed the sample contained $\mathrm{Sn}$ and $\mathrm{Ag}$ as major products with a little bit of $\mathrm{SnO}$ according to the atomic percentage of $\mathrm{Sn}, \mathrm{Ag}$ and $\mathrm{O}$ which are $51.64 \%, 14.82 \%$ and $33.54 \%$ respectively. In FTIR analysis, succinate was proven to be present in the Sn/Ag NPs composite sample synthesized as functional groups such as $\mathrm{O}-\mathrm{H}$ stretching, $\mathrm{C}-\mathrm{H}$ stretching and $\mathrm{C}=\mathrm{O}$ stretching is identified at adsorption bands of $3438.90 \mathrm{~cm}^{-1}, 2920.72 \mathrm{~cm}^{-1}$ and $1558.38 \mathrm{~cm}^{-1}$, respectively. In TEM analysis, the estimated particle size of $\mathrm{Sn} / \mathrm{Ag}$ NPs composite was $4.37 \pm 0.44 \mathrm{~nm}$. The lattice distances which coincide to metallic $\mathrm{Sn}(0.318 \mathrm{~nm})$ and $\mathrm{Ag}(0.408 \mathrm{~nm})$ were found in TEM analysis. However, the role of sodium succinate as protective agent was not so effective because FESEM analysis shows Sn and $\mathrm{Sn} / \mathrm{Ag}$ NPs are agglomerated. For the application of electro-catalytic behaviour, Sn/Ag NPs composite has a higher efficiency than Sn NPs because based on LSV analysis, Sn/Ag NPs composite could produce current of $4.10 \times 10^{-6} \mathrm{~A}$ which is more than current of $3.47 \times 10^{-6} \mathrm{~A}$ produced by Sn NPs. Hence, Sn/Ag NPs composite has the potential to act as high-performance electro-catalyst for polymer electrolyte fuel cell.

\section{Funding}

This research was funded by Takasago Thermal Engineering Co. Ltd. grant (\#4B422) from the research management center (RMC) of Universiti Teknologi Malaysia (UTM) and Malaysia-Japan International Institute of Technology (MJIIT).

\section{Acknowledgement}

The authors thank colleagues and collaborators who have contributed to the development of this work. 


\section{References}

1. Sharma, G.; Kumar, D;. Kumar, A.; Al-Muhtaseb, A.H.; Pathania, D.; Naushad, M.; Mola, G.T. Revolution from monometallic to trimetallic nanoparticle composites, various synthesis methods and their applications: A review. Mater. Sci. Eng. C 2017, 71, 1216-1230. doi.org/10.1016/j.msec.2016.11.002

2. Ahmad, M.; Shameli, K.; Zargar, M. Synthesis and antibacterial activity of silver/montmorillonite nanocomposites. Res. J. Biol. Sci. 2009, 4(9), 1032-1036. doi.org/10.2147/IJN.S16043

3. Jazayeri, S.D.; Ideris, A.; Zakaria, Z.; Shameli, K.; Moeini, H.; Omar, A.R. Cytotoxicity and immunological responses following oral vaccination of nanoencapsulated avian influenza virus H5 DNA vaccine with green synthesis silver nanoparticles. J Control Release 2012, 1, 116-123. doi.org/10.1016/j.jconrel.2012.04.015

4. Balavandy, S.K.; Shameli, K,; Abidin, Z.Z. Rapid and green synthesis of silver nanoparticles via sodium alginate media. Int. J. Electrochem. Sci. 2015, 1, 486-497.

5. Ismail, S.; Jalilian, F.A, Talebpur, A.H.; Zargar, M.; Shameli, K. Chemical composition and antibacterial and cytotoxic activities of Allium hirtifolium Boiss. BioMed Res. Int. 2013, 2013, 1-9. doi.org/10.1155/2013/696835

6. Khandanlou, R.; Ahmad, M.; Fard-Masoumi, H.R.; Shameli,K.; Basri, M. Rapid adsorption of copper (II) and lead (II) by rice straw $/ \mathrm{Fe}_{3} \mathrm{O}_{4}$ nanocomposite: optimization, equilibrium isotherms, and adsorption kinetics study. Pols one 2015, 10(3), doi.org/1-9. 10.1371/journal.pone.0120264

7. Miyabayashi, K.; Higashimoto, M.; Shen, Z.; Miyake, M. Site specific deposition of Ag on the corners of Pt nanocubes. Chem. Lett. 2011, 40, 705-707. doi.org/10.1246/cl.2011.705

8. Chavan, S.; Talange, D. Modeling and performance evaluation of PEM fuel cell by controlling its input parameters. Energy 2017, 138, 437-445. doi.org/10.1016/j.energy.2017.07.070

9. Özgür, T.; Yakaryılmaz, A.C. A review: Exergy analysis of PEM and PEM fuel cell based CHP systems. Int. J. Hydrog. Energy 2018, 43(38), 17993-18000. doi.org/10.1016/j.ijhydene.2018.01.106

10. Shao, M.; Chang, Q.; Dodelet, J.; Chenitz, R. Recent Advances in Electrocatalysts for Oxygen Reduction Reaction. Chem. Rev. 2016, 116(6), 3594-3657. doi.org/10.1021/acs.chemrev.5b00462

11. Shao, M. Palladium-based electrocatalysts for hydrogen oxidation and oxygen reduction reactions. J. Power Sources 2011, 196(5), 2433-2444. doi.org/10.1016/j.jpowsour.2010.10.093

12. Wang, C.; Daimon, H.; Sun, S. Dumbbell-like $\mathrm{Pt}-\mathrm{Fe}_{3} \mathrm{O}_{4}$ nanoparticles and their enhanced catalysis for oxygen reduction reaction. Nano Lett. 2009, 9(4), 1493-1496. doi.org/10.1021/nl8034724

13. Esfandiari, A.; Kazemeini, M.; Bastani, D. Synthesis, characterization and performance determination of an Ag@Pt/C electrocatalyst for the ORR in a PEM fuel cell. Int. J. Hydrog. Energy 2016, 41(45), 20720-20730. doi.org/10.1016/j.ijhydene.2016.09.097

14. Zhang, Y.; Li, X.; Li, K.; Xue, B.; Zhang, C.; Du, C.; Wu, Z.; Chen, W. Novel Au catalysis strategy for the synthesis of Au@Pt core-shell nanoelectrocatalyst with self-controlled quasi-monolayer Pt skin. ACS Appl. Mater. Interfaces 2017, 9(38), 32688-32697. doi.org/10.1021/acsami.7b08210

15. Zhang, H.; Song, Y.; Liang, Z.; Zhang, X.; B. Xu, Guo, J. A novel Sn/SnO/graphene triple core-shell heterogeneous catalyst for oxygen reduction reaction. Inorg. Chem. Commun. 2018, 96, 101-105. doi.org/10.1016/j.inoche.2018.07.046

16. Cheng, Y.; Tian, Y.; Tsang, S. Yan, C. Ag nanoparticles on boron doped multi-walled carbon nanotubes as a synergistic catalysts for oxygen reduction reaction in alkaline media. Electrochim. Acta 2015, 174, 919doi.org/924. 10.1016/j.electacta.2015.05.183

17. Xiao, D.; Ma, J.; Chen, C.; Luo, Q.; Ma, J.; Zheng, L.; Zuo, X. Oxygen-doped carbonaceous polypyrrole nanotubes-supported Ag nanoparticle as electrocatalyst for oxygen reduction reaction in alkaline solution. Mater. Res. Bull. 2018, 105, 184-191. doi.org/10.1016/j.materresbull.2018.04.030

18. Linge, J.M.; Erikson, H.; Kozlova, J.; Sammelselg, V.; Tammeveski, K. Oxygen reduction reaction on electrochemically depositedsilver nanoparticles from non-aqueous solution. J. Electroanal. Chem. 2018, 810, 129-134. doi.org/10.1016/j.jelechem.2018.01.009

19. Stamenović, U.; Gavrilov, N.; Pašti, I.A.; Otoničar, M.; Ćirić-Marjanović, G. Škapin, S.D.; Mitrić, M.; Vodnik, V. One-pot synthesis of novel silver-polyaniline-polyvinylpyrrolidone electrocatalysts for 
efficient oxygen reduction reaction. Electrochim. Acta 2018, 281, 549-561. doi.org/10.1016/j.electacta.2018.05.202

20. Chen, Y.; Liu, S.; Yu, L.; Liu, Q.; Wang, Y.; Dong, L. Efficient carbon-supported Ag-MFe2 $\mathrm{O}_{4}(\mathrm{M}=\mathrm{CO}, \mathrm{Mn})$ core-shell catalysts for oxygen reduction reactions in alkaline media. Int. J. Hydrogen Energy 2017, 42, doi.org/11304-11311. 10.1016/j.ijhydene.2017.03.088

21. Fu, T.; Huang, J.; Lai, S.; Zhang, S.; Fang, J.; Zhao, J. Pt skin coated hollow Ag-Pt bimetallic nanoparticles with high catalytic activity for oxygen reduction reaction. J. Power Sources 2017, 365, 17-25. doi.org/10.1016/j.jpowsour.2017.08.066

22. Hernández-Rodríguez, M.; Goya, M.; Arévalo, M.; Rodríguez, J.; Pastor, E. Carbon supported Ag and AgCo catalysts tolerant to methanol and ethanol for the oxygen reduction reaction in alkaline media. Int. J. Hydrog. Energy 2016, 41(43), 19789-19798. doi.org/10.1016/j.ijhydene.2016.07.188

23. Cao, J.; Guo, M.; Wu, J.; Xu, J.; Wang, W.; Chen, Z. Carbon-supported Ag@Pt core-shell nanoparticles with enhanced electrochemical activity for methanol oxidation and oxygen reduction reaction. J. Power Sources 2015, 277, 155-160. doi.org/10.1016/j.jpowsour.2014.12.017

24. Ruiz-Camacho, B.; Martínez Álvarez, O.; Rodríguez-Santoyo, H.H.; López-Peréz, P.A.; Fuentes-Ramírez, R. Mono and bi-metallic electrocatalysts of $\mathrm{Pt}$ and $\mathrm{Ag}$ for oxygen reduction reaction synthesized by sonication. Electrochem. Commun. 2015, 61, 5-9. doi.org/10.1016/j.elecom.2015.09.023

25. Cheng, Y.; Li, W.; Fan, X.; Liu, J.; Xu, W.; Yan, C. Modified multi-walled carbon nanotube/Ag nanoparticle composite catalyst for the oxygen reduction reaction in alkaline solution. Electrochim. Acta 2013, 111, 635641. doi.org/10.1021/jp022505c

26. Lim, E.J.; Choi, S.M.; Seo M.H.; Kim, Y.; Lee, S.; Kim, W.B. Highly dispersed Ag nanoparticles on nanosheets of reduced graphene oxide for oxygen reduction reaction in alkaline media. Electrochem. Commun. 2013, 28, 100-103. doi.org/10.1016/j.elecom.2012.12.016

27. Huang, X.; Zhang, H.; Guo, C.; Zhou, Z.; Zheng, N. Simplifying the creation of hollow metallic nanostructures: One-pot synthesis of hollow palladium/platinum single-crystalline nanocubes. Angew. Chem. Int. Ed. 2009, 48(26), 4808-4812. doi.org/10.1002/anie.200900199

28. Chee, S.; Lee, J. Synthesis of sub-10-nm Sn nanoparticles from Sn(II) 2-ethylhexanoate by a modified polyol process and preparation of AgSn film by melting of the Sn nanoparticles. Thin Solid Films 2014, 562, 211217. doi.org/10.1016/j.tsf.2014.04.061

29. Wang, L., Chen, L., Yan, B., Wang, C., Zhu, F., Jiang, X., Chao, Y.; Yang, G. In situ preparation of SnO2@polyaniline nanocomposites and their synergetic structure for high-performance supercapacitors. J. Mater. Chem. A 2014, 2(22), 8334-8341. doi.org/10.1039/C3TA15266A

30. Kelgenbaeva, Z.; Omurzak, E.; Ihara, H.; Iwamoto, C.; Sulaimankulova, S.; Mashimo, T. Sn and SnO2 nanoparticles by pulsed plasma in liquid: Synthesis, characterization and applications. Phys. Status Solidi A 2015, 212(12), 2951-2957. doi.org/10.1002/pssa.201532502.

31. Chen, P-J.; Jeng, H-T. Phase diagram of the layered oxide SnO: GW and electron-phonon studies. Sci. Rep. 2015, 5(16359). doi.org/10.1038/srep16359.

32. Singh, J.; Girothia, A.; Mandre, K.; Kaurav, N.; Okram, G. Trioctylphosphine and oleylamine induced thermoelectric power of Ag nanoparticles. J. Phys. Conf. Ser. 2014, 534(012035). doi:10.1088/17426596/534/1/012035 